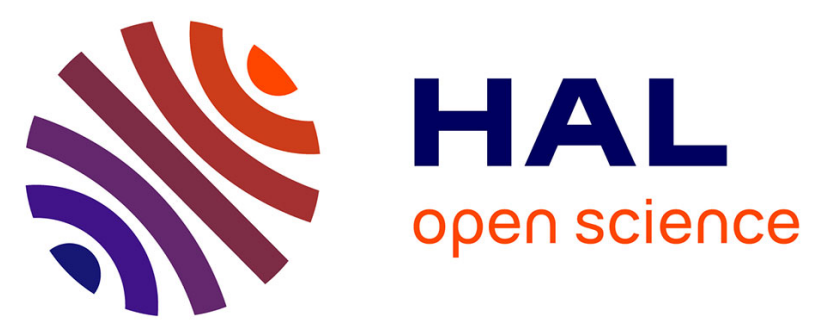

\title{
Prevalence and clinical impact of autoimmune diseases and chronic infections in malignant lymphomas at diagnosis
}

Katrina Vanura, Florentin Späth, Andreas Gleiss, Trang Le, Edit Porpaczy, Cathrin Skrabs, Alexander Hauswirth, Karin Fleiss, Florian Wessely,

Alexander Gaiger, et al.

\section{To cite this version:}

Katrina Vanura, Florentin Späth, Andreas Gleiss, Trang Le, Edit Porpaczy, et al.. Prevalence and clinical impact of autoimmune diseases and chronic infections in malignant lymphomas at diagnosis. Annals of Hematology, 2011, 90 (8), pp.947-954. 10.1007/s00277-011-1178-3 . hal-00615424

\section{HAL Id: hal-00615424 https://hal.science/hal-00615424}

Submitted on 19 Aug 2011

HAL is a multi-disciplinary open access archive for the deposit and dissemination of scientific research documents, whether they are published or not. The documents may come from teaching and research institutions in France or abroad, or from public or private research centers.
L'archive ouverte pluridisciplinaire HAL, est destinée au dépôt et à la diffusion de documents scientifiques de niveau recherche, publiés ou non, émanant des établissements d'enseignement et de recherche français ou étrangers, des laboratoires publics ou privés. 


\section{Prevalence and clinical impact of autoimmune diseases and chronic infections in malignant lymphomas at diagnosis}

Katrina Vanura ${ }^{1 *}$, Florentin Späth ${ }^{1 *}$, Andreas Gleiss ${ }^{2}$, Trang Le ${ }^{1}$, Edit Porpaczy ${ }^{1}$, Cathrin Skrabs ${ }^{1}$, Alexander Hauswirth ${ }^{1}$, Karin Fleiß ${ }^{1}$, Florian Wessely ${ }^{1}$, Alexander Gaiger ${ }^{1}$, Leonhard Müllauer $^{3}$, and Ulrich Jäger ${ }^{1}$

${ }^{1}$ Department of Internal Medicine I, Division of Hematology and Hemostaseology, Comprehensive Cancer Center (CCC)

${ }^{2}$ Center for Medical Statistics, Informatics and Intelligent Systems;

${ }^{3}$ Clinical Institute of Pathology;

Medical University of Vienna, Währinger Gürtel 18-20, A-1090 Vienna, Austria.

* These authors contributed equally to the manuscript.

\section{Correspondence:}

Ulrich Jäger

Department of Internal Medicine I, Division of Hematology and Hemostaseology

Medical University of Vienna

Währinger Gürtel 18-20

A-1090 Vienna, Austria;

Phone: $+43 / 1 / 40400 / 4409$

Fax: $+43 / 1 / 40400 / 4030$

E-mail: ulrich.jaeger@meduniwien.ac.at 


\section{ABSTRACT}

There is increasing evidence for the role of chronic antigenic stimulation (CS) in the development of cancer. Clinical data, however, are rare as is the information on outcome. In this study, the occurrence of chronic infections $(\mathrm{Cl})$ and autoimmune diseases $(\mathrm{Al})$ in patients with malignant lymphoma at diagnosis was assessed. Of 367 patients (non-Hodgkin's lymphoma (NHL) N=297, Hodgkin's lymphoma (HL) N=70), 9.8\% (N=36) had a history of chronic antigenic stimulation $(4.4 \% \mathrm{Al}, 5.4 \% \mathrm{Cl})$ at diagnosis. After a median observation time of 74.7 months, 118 patients have died. There were more male patients in this cohort. However, sex ratio among patients with chronic antigenic stimulation was skewed in favor of women $(p=0.018)$, in particular among lymphoma patients with $\mathrm{Al}(\mathrm{p}=0.001)$. NHL patients with autoimmune diseases showed a tendency to develop diffuse large B cell lymphoma

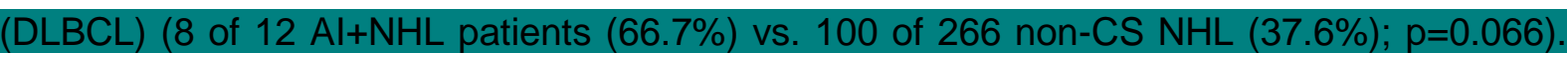
No significant difference in overall survival (OS) between CS and non-CS patients could be observed (median OS after 48 months was: CS $77.7 \%$ vs. non-CS $71.8 \%$ ).

In conclusion, chronic antigenic stimulation at diagnosis appears to be associated with a higher prevalence in women, in particular among patients with autoimmune disease. However, no difference in overall survival was observed. This suggests that the presence of chronic inflammatory conditions does not decisively influence the outcome of lymphoma patients.

Keywords

Iymphoma; autoimmune diseases; chronic infections; prevalence; therapy 


\section{INTRODUCTION}

Malignant lymphomas are neoplasms of the lymphoid system characterized by a wide range of biological, pathological, and epidemiological features thus showing heterogeneous clinical presentation and behavior [1]. Two major groups of malignancies can be distinguished, Hodgkin's lymphoma (HL) and non-Hodgkin's lymphomas (NHL). Incidences are 3/100.000 for $\mathrm{HL}$ and 10/100.000 for NHL per year in Western Countries, respectively, both subgroups have a male predominance (1.5-2:1) [2], and the number of incidences is increasing [3]. The etiology of lymphomas is largely unknown. However, development may be accompanied by altered immunological functions, either chronic antigenic stimulation (CS) (chronic infections $(\mathrm{Cl})$, autoimmune disease $(\mathrm{Al})$ ) or immunosuppression (immunodeficiencies, transplant patients) [3, 4]. In particular, autoimmune diseases have repeatedly been shown to confer an increased risk for certain hematologic malignancies [5, 6]. Linking infectious agents with neoplasia, however, is a more difficult task. To demonstrate a causal relationship between a microorganism and the development of a disease, certain criteria have to be fulfilled $[7,8]$. Thus, Epstein-Barr virus (EBV), human herpes virus 8, human T-lymph tropic virus type I, human immunodeficiency virus, Plasmodium falciparum, hepatitis $\mathrm{C}$ virus, hepatitis $\mathrm{B}$ virus, Helicobacter pylori, Campylobacter jejuni, Chlamydia psittaci, and Borrelia burgdorferi have been shown to be associated with malignant lymphoma (reviewed by Hjalgrim [9]). The common theme in these settings is a state of persistent foreign- or auto-antigenic stimulation initiating inflammatory responses. The accelerated expansion of particular cell populations involves an increased risk for genetic lesions and/or functional errors which may perturb balance and interactions of immune cell compartments. Accumulation of additional transforming events may then trigger malignant progression of lymphoid clones leading to lymphoma or leukemia (see also Fisher \& Fisher [10])

Considering the tight association of $\mathrm{Al}$ and $\mathrm{Cl}$ with hematologic malignancies, surprisingly few data are available regarding the prevalence of CS in lymphoma patients. Also, it is still largely unclear how and to which degree CS influences the course of the disease in terms of prognosis and treatment. Therefore, we investigated the occurrence of chronic infectious and autoimmune diseases in patients with malignant lymphoma. These data were correlated with age, sex, type of disease, the international prognostic index for $\mathrm{NHL}$, and overall survival (OS).

\section{MATERIALS AND METHODS}

\section{Patients}


This is a retrospective, monocentric study performed at the Division of Hematology and Hemostaseology of the Medical University of Vienna. In total, 574 patients with malignant Jymphoma were diagnosed at the unit between 2001 and 2005. Of note, this number does not include patients with chronic lymphocytic leukemia (CLL) and MALT lymphoma since results for these entities were published elsewhere [11, 12]. Of 574 patients, 94 were excluded from the analysis because of underlying immunosuppression (HIV positivity, post transplant lymphoproliferative disorder, common variable immunodeficiency) or because they were classified as primary CNS lymphomas. Of the remaining 480 patients, 386 suffered from Non-Hodgkin's and 94 from Hodgkin's lymphoma. Due to insufficient survival data, the number of patients was reduced to 297 and 70 for NHL and HL, respectively. Thus, a total of 367 patient records were analyzed for this study.

Patients were considered having chronic conditions only if specific medical records or laboratory data or both were available. Patient data collected included: sex, age, mortality, lymphoma subtype, international prognostic index, and treatment. Lymphomas studied were diffuse large B cell lymphoma (DLBCL), follicular lymphoma (FL), mantle cell lymphoma (MCL), T-cell neoplasms (PTCL - peripheral T-cell lymphoma; T-ALCL - T-cell anaplastic large cell lymphoma, T-LGL - T-cell large granular lymphocytic leukemia), marginal zone lymphoma (MZL; splenic and nodal subtypes), small lymphocytic lymphoma (SLL), lymphoplasmacytic lymphoma (LPL), and unclassifiable B-cell lymphoma with features intermediate between DLBCL and Burkitt lymphoma (ICD-O code 9680/3 [13]). Rare subtypes and unspecified types of lymphomas were combined as "other B cell lymphomas". DLBCL, FL grade 3, high grade unclassifiable B-cell lymphoma, PTCL, and T-ALCL were defined as aggressive, the remaining malignancies as indolent lymphoma subtypes. Chronic infections were defined as chronic or recurrent conditions caused by an infectious agent at least 6 months prior to lymphoma diagnosis and included: chronic colitis (CC), Epstein-Barr virus (EBV), hepatitis C virus (HCV), hepatitis B virus (HBV), Helicobacter pylori (HP) gastritis, lues latens (Treponema infection; LL), and chronic respiratory tract infections (RTI). Autoimmune diseases included were: systemic lupus erythematosus (SLE), rheumatoid arthritis (RA), Hashimoto's thyroiditis (HT), ulcerative colitis (UC), urticarial vasculitis (UV), idiopathic thrombocytopenic purpura (ITP), Sjögren's syndrome (SS), and atopic dermatitis (AD). Patients received standard chemotherapeutic lymphoma treatment including CD20 antibody therapy or radiation according to guidelines and current clinical practice.

\section{Statistical analysis}

Categorical variables were described by absolute and relative frequencies and compared between groups using Chi-Square tests (or Fisher's Exact tests where necessary). Age was described by median and range due to its skewed distribution and compared between groups 
using Wilcoxon's rank-sum test. Overall survival (OS) was calculated from the time of diagnosis either until death or date last seen at the clinic and is represented graphically based on Kaplan-Meier estimates. Median observation time was estimated using the Inverse Kaplan-Meier method [14]. In order to quantify the potential effect of various factors on overall survival, a multi-variable Cox proportional-hazards model was used. The independent variables in this model comprise $\mathrm{CS}$ vs. non-CS, NHL vs. $\mathrm{HL}, \mathrm{Al}$ vs. $\mathrm{Cl}$, and gender. Furthermore, a variable was nested in the $\mathrm{NHL}$ group in order to distinguish aggressive from indolent lymphoma. Since this variable showed a time-dependent effect on overall survival, its interaction with log-time was also nested in the NHL-group. No other interaction of CS vs. non-CS was significant thus the CS-effect is the same for NHL and $\mathrm{HL}$ as well as for both sexes.

In order to evaluate the influence of incorporating International Prognostic Index (IPI) classification on the results of survival analysis, a three stage classification variable was used as stratification factor in a Cox model on a reduced data set. For this purpose, patients suffering from DLBCL and FL ( $\mathrm{N}=180$; data available for 141 patients) were classified into low, intermediate, and high risk groups (IPI 0-1 = low risk, IPI 2-3 = intermediate risk, IPI 4-5 = high risk) before the model was applied. Due to the low number of CS patients DLBCL and FL were analyzed together $(\mathrm{N}=23)$.

The reported $p$-values are the results of two-sided tests. $P$-values $\leq 0.05$ were considered to be statistically significant. All computations have been performed using SAS software Version 9.2 (SAS Institute Inc., Cary, NC, USA, 2008)

\section{RESULTS}

\section{General considerations}

In this study, 367 patients with malignant lymphoma were analyzed regarding a history of chronic antigenic stimulation. Of these patients, 70 suffered from HL. Patients with NHL $(\mathrm{N}=297)$ had diffuse large $\mathrm{B}$ cell lymphoma $(\mathrm{N}=115)$, follicular lymphoma $(\mathrm{N}=65)$, mantle cell lymphoma $(\mathrm{N}=21)$, T-cell neoplasms $(\mathrm{N}=19)$, marginal zone lymphoma $(\mathrm{N}=18)$, small lymphocytic lymphoma $(\mathrm{N}=14)$, lymphoplasmacytic lymphoma $(\mathrm{N}=9)$, Burkitt-like lymphoma $(\mathrm{N}=1)$, and other lymphomas $(\mathrm{N}=35)$. A history of chronic antigenic stimulation was found in 36 patients (9.8\%), 16 with $\mathrm{Al}(4.4 \%)$ and 20 with $\mathrm{Cl}(5.4 \%)$ (Tables $1 \mathrm{~A}$ and $1 \mathrm{~B})$. Al diseases found were SLE $(\mathrm{N}=4 ; 1.1 \%)$, Hashimoto's thyroiditis $(\mathrm{N}=3 ; 0.8 \%)$, RA $(\mathrm{N}=3 ; 0.8 \%)$, ulcerative colitis $(\mathrm{N}=2 ; 0.5 \%)$, atopic dermatitis $(\mathrm{N}=1 ; 0.3 \%)$, ITP $(\mathrm{N}=1 ; 0.3 \%)$, Sjögren's syndrome $(\mathrm{N}=1 ; 0.3 \%)$, and urticarial vasculitis $(\mathrm{N}=1 ; 0.3 \%)$. Cl included respiratory tract infections $(\mathrm{N}=6 ; 1.6 \%)$, HCV $(\mathrm{N}=5 ; 1.4 \%)$, HBV $(\mathrm{N}=3 ; 0.8 \%)$, HP gastritis $(\mathrm{N}=3 ; 0.8 \%)$, 
chronic colitis $(\mathrm{N}=1 ; 0.3 \%)$, EBV $(\mathrm{N}=1 ; 0.3 \%)$, and lues latens $(\mathrm{N}=1 ; 0.3 \%)$. One $\mathrm{HL}$ patient with RA had concomitant RTI. This patient was classified under Al because, in our opinion, $\mathrm{Al}$ outweighs $\mathrm{Cl}$. CS diseases as found per lymphoma subtype are listed in Tables $1 \mathrm{~A}$ and 1B. One hundred eighteen patients have died, the median observation period was 74.7 months (quartiles: 62.6 to 89.1 months). No significant difference in overall survival between CS and non-CS patients was observed (HR 0.63, 95\% confidence interval 0.26 - 1.54; $\mathrm{p}=0.311$ ). Kaplan-Meier estimates for survival after 48 months were $77.7 \%$ in CS vs. $71.8 \%$ in non-CS patients (HL: CS 100.0\%, non-CS 88.7\%; aggressive NHL: CS 66.7\%, non-CS $58.6 \%$; indolent NHL: CS $84.6 \%$, non-CS $77.0 \%$; $p=0.311$ ). Patient characteristics are listed in Table 2. Median age at diagnosis of lymphoma was 57.0 years for CS patients and 59.7 years for non-CS patients $(\mathrm{p}=0.775)$.

\section{Sex-specific differences}

We found a slight male predominance in this patient cohort, men constituting $51.7 \%(\mathrm{~N}=190)$ of patients compared to $48.2 \%$ women $(\mathrm{N}=177)$. Considering CS patients only, however, there was a significant prevalence of women $(66.7 \%$ or $\mathrm{N}=24)$ compared to the non-CS group (45.9\% or $\mathrm{N}=152)(\mathrm{p}=0.018)$ which was due to an overrepresentation of women in the Al group (87.5\%; $N=14)(p=0.001)$. In the $\mathrm{Cl}$ group, no gender bias was found (50\% women; $\mathrm{N}=10 ; \mathrm{p}=0.851)$. The effect of CS vs. non-CS on OS was the same in both sexes $(\mathrm{p}=0.249)$

\section{NHL - antigenic stimulation}

Twelve patients with $\mathrm{NHL}$ had a history of $\mathrm{Al}, 19$ showed $\mathrm{Cl}$. This corresponds to $4.1 \%$ and $6.4 \%$ of $297 \mathrm{NHL}$ patients, respectively. Most frequent Al were SLE $(\mathrm{N}=4 ; 1.35 \%)$ and $\mathrm{HT}$ $(\mathrm{N}=2 ; 0.67 \%)$. Among $\mathrm{Cl}, \mathrm{RTI}(\mathrm{N}=6 ; 2.02 \%)$ ranked top followed by $\mathrm{HCV}(\mathrm{N}=5 ; 1.68 \%), \mathrm{HBV}$ $(\mathrm{N}=3 ; 1.01 \%)$ and $\mathrm{HP}(\mathrm{N}=3 ; 1.01 \%)$. For a complete list see Table $1 \mathrm{~A}$.

Considering $\mathrm{NHL}$ subtypes, $58.1 \%(\mathrm{~N}=18)$ of $\mathrm{CS}$ patients suffered from an aggressive lymphoma of $\mathrm{B}$-cell type compared to $51.1 \%(\mathrm{~N}=133)$ of patients without antigenic stimulation $(p=0.395)$. Among Al patients only, the prevalence of an aggressive subtype was $75 \%(N=9$ of 12), among $\mathrm{Cl}$ patients 9 of 19 had aggressive lymphomas (47.4\%). DLBCL was slightly more prevalent in the CS group than in the non-CS group $(48.4 \%$ vs. $37.6 \%)(p=0.243)$. Among CS patients, notably persons suffering from autoimmune diseases showed a high rate of DLBCL $(66.7 \%$ vs. $37.6 \%$ of non-CS patients $)(p=0.066)$. The effect of CS on OS was not significantly different, being the same in indolent and aggressive lymphomas ( $\mathrm{HR}=0.63, \mathrm{p}=0.311)$ (Fig. 1).

Additional lymphomas found in the CS group were: $\mathrm{FL}(\mathrm{N}=8$ or $26 \%$ ), MCL ( $\mathrm{N}=4$ or $13 \%)$, MZL ( $\mathrm{N}=2$ or $6 \%$ ), and other $\mathrm{B}$ cell lymphomas ( $\mathrm{N}=2$ or $6 \%$ ). Of note, MCL and MZL cases were associated with $\mathrm{Cl}$ only. In the case of $\mathrm{MZL}$, the low number may be explained by the 
fact that MALT lymphomas were not included in this study. Among SLL, T-cell neoplasms (PTCL, T-ALCL, T-LGL), and LPL, no history of $\mathrm{Al}$ or $\mathrm{Cl}$ was found. Median age at NHL diagnosis was lower in CS patients (60.1 vs. 62.4 years; $p=0.203$ ).

To include prognostic markers in the model, patients with the most frequent histologies, DLBCL and FL, were risk stratified based on the international prognostic index. The percentage of CS patients in the risk groups were $11.4 \%, 8.2 \%$, and $15.4 \%$ for low, intermediate and high risk group, respectively $(\mathrm{p}=0.711)$. Incorporating IPI risk stratification in the Cox model resulted in a comparable hazard ratio for CS patients of $0.58(\mathrm{Cl} 0.18-1.90$; $\mathrm{p}=0.371)$.

\section{NHL - sex-specific differences}

As expected, men were predominant in the entire patient cohort ( $N=154$ vs. $143 ; 51.8 \%$ vs. $48.1 \%)$. In patients with CS, however, the sex ratio was skewed in favor of women ( $N=21$ vs. $10 ; 67.7 \%$ vs. $32.3 \%)(p=0.021)$. Sex had no significant influence on OS ( $p=0.072)$, albeit men had a slightly better OS than women (HR 0.71, 95\% confidence intervals $0.50-1.03$ ). Interestingly, CS men showed the best OS compared to all other groups. Non-CS men, and CS and non-CS women had comparable OS (Fig. 2). However, the effect of CS vs. non-CS on OS was not significantly different for the two sexes, being thus in both genders HR=0.63 $(p=0.311)$.

\section{$H L$ - antigenic stimulation}

Five patients out of 70 persons with $\mathrm{HL}(7.1 \%)$ were found to have a history of CS, 4 with $\mathrm{Al}$ (5.6\%) and 1 with $\mathrm{Cl}(1.4 \%)$ (Table 1B). Chronic diseases found were RA (N=2; $2.8 \%)$, HT $(\mathrm{N}=1 ; 1.4 \%)$, and $\mathrm{UC}(\mathrm{N}=1 ; 1.4 \%)$. The single patient with $\mathrm{Cl}$ had EBV infection $(1.4 \%)$. Histological data on LMP1 expression were available for 32/70 patients, 31 were negative, a single patient was LMP1 positive. As in NHL, CS conferred a slight advantage for OS in HL patients (OR 0.63, 95\% confidence intervals $0.26-1.54, \mathrm{p}=0.311$ ). Median age at diagnosis was 53.1 years for CS patients and 34.5 years for non-CS patients $(p=0.454)$.

\section{$H L$ - sex-specific differences}

Sex distribution of the entire cohort were $51.4 \%$ men and $48.5 \%$ women ( $N=36$ vs. $N=34$ ). The CS group consisted of three women and two men (60\% vs. $40 \%)$, within the non-CS group, women constituted $48 \%(\mathrm{~N}=31)$, men $52 \%(\mathrm{~N}=34)$.

\section{DISCUSSION}

Chronic antigenic stimulation has long been implicated in the development of non-HIV associated hematologic malignancies. Reasons are the observed prevalence and the 
increased risk of cancer particularly among patients with autoimmune diseases and the association of some infectious agents with certain malignancies.

In this study, we found a prevalence of $9.8 \%$ for a history of chronic stimulation in a cohort of 367 malignant lymphoma patients, rates being almost equal for $\mathrm{Al}$ and $\mathrm{Cl}$. Published estimates of $\mathrm{Al}$ prevalence in the general population range between 3 and $10 \%$ [15-17] and was reported to lie between 5 and $8 \%$ within the US population [18]. The prevalence of $4.4 \%$ of $\mathrm{Al}$ in our study cohort, thus, is in concordance with these reports for Western countries. Only for SLE, a higher prevalence was observed compared to the general population $(1.1 \%$ vs. $0.02 \%-0.04 \%$ ) $[17,19]$. The prevalence of $4 \% \mathrm{Al}$ among our NHL patients, however, was lower compared to a study published by Cuttner who found $13 \%$ of NHL patients to have a history of Al compared to $5 \%$ of controls [20]. Of note, Cuttner and colleagues analyzed HL and CLL patients with the control group. Other studies reported 39\% Al among MALT lymphoma patients [11], and $16 \%$ and $11.8 \%$, respectively, in CLL [12, 21]. In all three studies, Al patients with malignant diseases were predominantly women.

According to the Austrian Ministry of Health, the prevalence of HCV in Austria is $0.7 \%$ and that of HBV is even lower. In this study cohort, HCV and HBV constituted $1.4 \%(\mathrm{~N}=5)$ and $0.8 \%(\mathrm{~N}=3)$ of patients, respectively, which would indicate a 2 -fold overrepresentation compared to the general population. On the other hand, conflicting results have been obtained regarding the frequency of such infections among lymphoma patients from other countries. Some studies found no association of HCV or HBV infections with NHL [22-24], other studies found a higher prevalence of hepatitis C and B in NHL patients compared to controls [25-27]. This has, in part, been ascribed to different rates of hepatitis infections in the general population of the respective countries. Wang reported a decreased rate of HBV infections in patients with T-cell lymphoma compared to patients with B-cell malignancies [28].

In our study, SLL and T-cell lymphoma patients were not found to have a history of chronic stimulation, neither did LPL patients. This probably is due to the low patient numbers for these disease entities and the low prevalence of $\mathrm{Al}$ in general.

Considering the entire patient cohort, men were only slightly overrepresented compared to women (52 vs. 48\%), and this distribution of sexes did not change when analyzing NHL and HL separately. However, among CS patients women predominated which was due to an overrepresentation of women in the Al group (87.5\%). Due to few CS patients, this difference was not statistically significant in $\mathrm{HL}$.

Median age at diagnosis of CS and non-CS patients was not statistically different in any of the groups. While among NHL patients non-CS patients were slightly older, the reverse was observed in HL patients where non-CS patients were much younger than CS patients. HL is known to have a bimodal distribution, one peak at an age of about 30 years and a second 
peak at 50 years and older [9], the most striking difference being that $\mathrm{HL}$ in young adults is less likely associated with EBV compared to the older age group [29]. The results here are in concordance with the reported distribution of $\mathrm{HL}$ in developed countries, where etiological agents responsible for $\mathrm{HL}$ incidence in the young adult age group remain to be elucidated [29]. Still, it is notable that only 1 of $70 \mathrm{HL}$ patients had concomitant clinical EBV infection, the other CS patients suffering from autoimmune disorders.

While CS patients were more often found to have an aggressive type of lymphoma, there was no significant difference in overall survival between CS and non-CS patients. The same was observed in indolent and aggressive subtypes and in both sexes. To assess for an association with known prognostic markers, DLBCL and FL patients were risk classified according to the IPI and the data incorporated in the Cox model. Even after stratification, no significant deviations from the original model could be observed indicating a lack of prognostic relevance.

This study has some limitations. Rigid criteria were used with regard to classifying a patient as CS or non-CS. Due to missing laboratory data, the number of CS patients may be underestimated, and serological evidence was not obtained in all patients. Thus, confidence is placed in the diagnosing physician and in the data provided by the patient during the interview. Since chronic infections, particularly RTI, might be due to immunosuppression caused by lymphomagenesis, in some cases it will remain unclear whether $\mathrm{Cl}$ was preexisting or a result of the developing lymphoma. The prevalence of chronic antigenic stimulation may also be under- or overestimated due to this study not being a case-control study.

The major conclusion of this study is that the presence of chronic antigenic stimulation in general does not decisively influence the clinical outcome of lymphoma patients. This does not preclude that in some cases additional specific anti-inflammatory or anti-infectious treatment may be required.

\section{Acknowledgements:}

We want to thank Maria Kössler and Manuela Supparitsch for excellent technical assistance. This work was supported by the Austrian Federal Ministry of Science and Research through the Gen-AU-Child project (GZ 200.136/1 - VI/1/2005). 


\section{REFERENCES}

[1]. Swerdlow SH et al. WHO classification of Tumours of Haematopoietic and Lymphoid Tissues; 2008, pp 1-439.

[2]. Boyle P, Levin B. In Word Cancer Report. Boyle P, Levin B. Lyon: IARC Press; 2008, pp 1-524.

[3]. Müller AM, Ihorst G, Mertelsmann R, Engelhardt M. (2005) Epidemiology of non-Hodgkin's lymphoma (NHL): trends, geographic distribution, and etiology. Ann Hematol 84(1):1-12.

[4]. Hansen A, Lipsky PE, Dörner T. (2007) B-cell lymphoproliferation in chronic inflammatory rheumatic diseases. Nat Clin Pract Rheumatol 3(10):561-9.

[5]. Smedby KE, Askling J, Mariette X, Baecklund E. (2008) Autoimmune and inflammatory disorders and risk of malignant lymphomas - an update. J Intern Med 264(6):514-27.

[6]. Anderson LA, Gadalla S, Morton LM et al. (2009) Population-based study of autoimmune conditions and the risk of specific lymphoid malignancies. Int J Cancer 125(2):398-405.

[7]. Bradford Hill A. (1965) The enviroment and disease: association or causation? Proc Roy Soc Med 58:195-200.

[8]. Fredericks DN, Relman DA. (1996) Sequence-based identification of microbial pathogens: a reconsideration of Koch's postulates. Clin Microbiol Rev 9(1):18-33.

[9]. Hjalgrim H, Engels EA. (2008) Infectious aetiology of Hodgkin and non-Hodgkin lymphomas: a review of the epidemiological evidence. J Intern Med 264(6):537-48.

[10]. Fisher SG, Fisher RI. (2006) The emerging concept of antigen-driven lymphomas: epidemiology and treatment implications. Curr Opin Oncol 18(5):417-24.

[11]. Wöhrer S, Troch M, Streubel B et al. (2007) MALT lymphoma in patients with autoimmune diseases: a comparative analysis of characteristics and clinical course. Leukemia 21(8):1812-8.

[12]. Vanura K, Le T, Esterbauer $\mathrm{H}$ et al. (2008) Autoimmune conditions and chronic infections in CLL patients at diagnosis are associated with unmutated IgVH genes. Haematologica 93:1912-6.

[13]. Kluin PM et al. B-cell lymphomas, unclassifiable, with features intermediate between diffuse large B-cell lymphoma and Burkitt lymphoma. In WHO classification of Tumours of Haematopoietic and Lymphoid Tissues. Swerdlow SH et al. Lyon: International Agency for Research on Cancer; 2008, pp 265-6.

[14]. Schemper M, Smith TL. (1996) A note on quantifying follow-up in studies of failure time. Control Clin Trials 17(4):343-6.

[15]. Dooley MA, Hogan SL. (2003) Environmental epidemiology and risk factors for autoimmune disease. Curr Opin Rheumatol 15(2):99-103.

[16]. Invernizzi P, Pasini S, Selmi C, Gershwin ME, Podda M. (2009) Female predominance and X chromosome defects in autoimmune diseases. J Autoimmun 33(1):12-6.

[17]. Cooper GS, Bynum ML, Somers EC. (2009) Recent insights in the epidemiology of autoimmune diseases: improved prevalence estimates and understanding of clustering of diseases. $\mathrm{J}$ Autoimmun 33(3-4):197-207. 
[18]. Progress in Autoimmune Diseases Research. Report to Congress, National Institutes of Health, The Autoimmune Diseases Coordinating Committee. US Dept. of Health and Human Services; 2005, pp 1-146.

[19]. Hopkinson ND, Doherty M, Powell RJ. (1994) Clinical features and race-specific incidence/prevalence rates of systemic lupus erythematosus in a geographically complete cohort of patients. Ann Rheum Dis 53(10):675-80.

[20]. Cuttner J, Spiera H, Troy K, Wallenstein S. (2005) Autoimmune disease is a risk factor for the development of non-Hodgkin's lymphoma. J Rheumatol 32(10):1884-7.

[21]. Barcellini W, Capalbo S, Agostinelli RM et al. (2006) Relationship between autoimmune phenomena and disease stage and therapy in B-cell chronic lymphocytic leukemia. Haematologica 91(12):1689-92.

[22]. Pioltelli P, Gargantini L, Cassi E et al. (2000) Hepatitis C virus in non-Hodgkin's lymphoma. A reappraisal after a prospective case-control study of 300 patients. Am J Hematol 64:95-100.

[23]. Isikdogan A, Ayyildiz O, Dursun M, Tiftik N, Batun S, Muftuoglu E. (2003) Hepatitis C virus in patients with non-Hodgin's lymphoma in southeastern Anatolian region of Turkey: a prospective case-control study of 119 patients. Leuk Lymphoma 44:1745-7.

[24]. Morgensztern D, Rosado MF, Silva $O$ et al. (2004) Prevalence of hepatitis $C$ infection in patients with non-Hodgin's lymphoma in south Florida and review of the literature. Leuk Lymphoma 45:2459-64.

[25]. Cucuianu A, Patiu M, Duma M et al. (1999) Hepatits B and C virus infection in Romanian nonHodgkin's lymphoma patients. Br J Haematol 107:353-6.

[26]. Shirin H, Davidovitz $Y$, Avni $Y$ et al. (2002) Prevalence of hepatitis $C$ virus infection in patients with lymhoproliferative disorders. Isr Med Assoc J 4:24-7.

[27]. Mele A, Pulsoni A, Bianco E et al. (2003) Hepatitis C virus and B-cell non-Hodgkin lymphomas: an Italian multicenter case-control study. Blood 102:996-9.

[28]. Wang F, Xu RH, Han B et al. (2007) High incidence of hepatitis B virus infection in B-cell subtype non-Hodgkin lymphoma compared with other cancers. Cancer 109(7):1360-4.

[29]. Jarrett RF. (2003) Risk factors for Hodgkin's lymphoma by EBV status and significance of detection of EBV genomes in serum of patients with EBV-associated Hodgkin's lymphoma. Leuk Lymphoma 44 Suppl 3:S27-32. 
Table 1A: Incidence of chronic inflammatory conditions found in NHL patients in our study cohort ( $\mathrm{N}=297)$.

\begin{tabular}{|c|c|c|c|c|c|c|c|c|}
\hline \multicolumn{2}{|c|}{ non-CS patients } & \multirow{2}{*}{$\begin{array}{l}\text { Lymphoma } \\
\text { subtype }\end{array}$} & \multicolumn{2}{|c|}{ CS patients } & \multirow[b]{2}{*}{$\mathrm{Cl}$} & \multirow[b]{2}{*}{$\mathbf{N}$} & \multirow[b]{2}{*}{ Al } & \multirow[b]{2}{*}{$\mathbf{N}$} \\
\hline $\mathbf{N}$ & $\%^{*}$ & & $\mathbf{N}$ & $\%^{*}$ & & & & \\
\hline \multirow[t]{7}{*}{100} & 87.0 & DLBCL & 15 & 13.0 & HBV & 2 & $A D$ & 1 \\
\hline & & & & & $\mathrm{HCV}$ & 1 & HT & 1 \\
\hline & & & & & $\mathrm{HP}$ & 2 & RA & 1 \\
\hline & & & & & RTI & 2 & SLE & 3 \\
\hline & & & & & & & UC & 1 \\
\hline & & & & & & & UV & 1 \\
\hline & & & & & & $6.1 \%$ & & $6.9 \%$ \\
\hline \multirow[t]{5}{*}{57} & 87.7 & $\mathrm{FL}$ & 8 & 12.3 & HBV & 1 & $\mathrm{HT}$ & 1 \\
\hline & & & & & $\mathrm{HCV}$ & 2 & ITP & 1 \\
\hline & & & & & $\mathrm{LL}$ & 1 & SS & 1 \\
\hline & & & & & RTI & 1 & & \\
\hline & & & & & & $7.7 \%$ & & $4.6 \%$ \\
\hline \multirow[t]{4}{*}{17} & 81.0 & MCL & 4 & 19.0 & $\mathrm{HCV}$ & 1 & & \\
\hline & & & & & $\mathrm{HP}$ & 1 & & \\
\hline & & & & & RTI & 2 & & \\
\hline & & & & & & $19.0 \%$ & & \\
\hline \multirow[t]{3}{*}{16} & 88.9 & MZL & 2 & 11.1 & $\mathrm{HCV}$ & 1 & & \\
\hline & & & & & $\mathrm{RTI}$ & 1 & & \\
\hline & & & & & & $11.1 \%$ & & \\
\hline \multirow[t]{2}{*}{33} & 94.3 & Other lymphomas & 2 & 5.7 & $\mathrm{CC}$ & 1 & SLE & 1 \\
\hline & & & & & & $2.9 \%$ & & $2.9 \%$ \\
\hline 19 & 100.0 & T-cell neoplasms & - & & & & & \\
\hline 14 & 100.0 & SLL & - & & & & & \\
\hline 9 & 100.0 & LPL & - & & & & & \\
\hline 1 & 100.0 & $\begin{array}{l}\text { Unclassifiable B- } \\
\text { cell lymphoma }\end{array}$ & - & & & & & \\
\hline
\end{tabular}

${ }^{*}$ refers to the incidence of non-CS patients and CS-patient within lymphoma subtypes, respectively.

Table 1B: Incidence of chronic inflammatory conditions found in HL patients in our study cohort ( $\mathrm{N}=70)$.

\begin{tabular}{|c|c|c|c|c|c|c|c|c|}
\hline \multicolumn{2}{|c|}{ non-CS patients } & \multirow{2}{*}{$\begin{array}{c}\text { Lymphoma } \\
\text { subtype }\end{array}$} & \multicolumn{2}{|c|}{ CS patients } & \multirow[b]{2}{*}{$\mathrm{Cl}$} & \multirow[b]{2}{*}{$\mathbf{N}$} & \multirow[b]{2}{*}{ Al } & \multirow[b]{2}{*}{$\mathbf{N}$} \\
\hline $\mathbf{N}$ & $\%$ & & $\mathbf{N}$ & $\%$ & & & & \\
\hline \multirow[t]{3}{*}{65} & 92.9 & $\mathrm{HL}$ & 5 & 7.1 & EBV & 1 & HT & 1 \\
\hline & & & & & & & RA & 2 \\
\hline & & & & & & & UC & 1 \\
\hline
\end{tabular}

Abbreviations: $\mathrm{AD}$ - atopic dermatitis; $\mathrm{Al}$ - autoimmune disease; $\mathrm{CC}$ - chronic colitis; $\mathrm{Cl}$ - chronic infection; $\mathrm{FL} \mathrm{-} \mathrm{follicular} \mathrm{lymphoma;} \mathrm{DLBCL} \mathrm{-}$ diffuse large B cell lymphoma; EBV - Epstein-Barr virus; HCV, HBV - hepatitis C / B virus; HL - Hodgkin's Lymphoma; HT - Hashimoto's thyroiditis; ITP - immune thrombocytopenia; LL - lues latens; LPL - lymphoplasmacytic lymphoma /Morbus Waldenström; MCL - mantle cell lymphoma; MZL -marginal zone lymphoma (splenic and nodal types); N - number of patients; RA - rheumatoid arthritis; RTI - respiratory tract infections; SLE - systemic lupus erythematosus; SS - Sjögren's syndrome; T-cell neoplasms - PTCL (peripheral T-cell lymphoma), T-ALCL (T-cell anaplastic large cell lymphoma), T-LGL (T-cell large granular lymphocytic leukemia); UC - ulcerative colitis; UV - urticarial vasculitis. 
Table 2: Characteristics of CS and non-CS patients with malignant lymphomas.

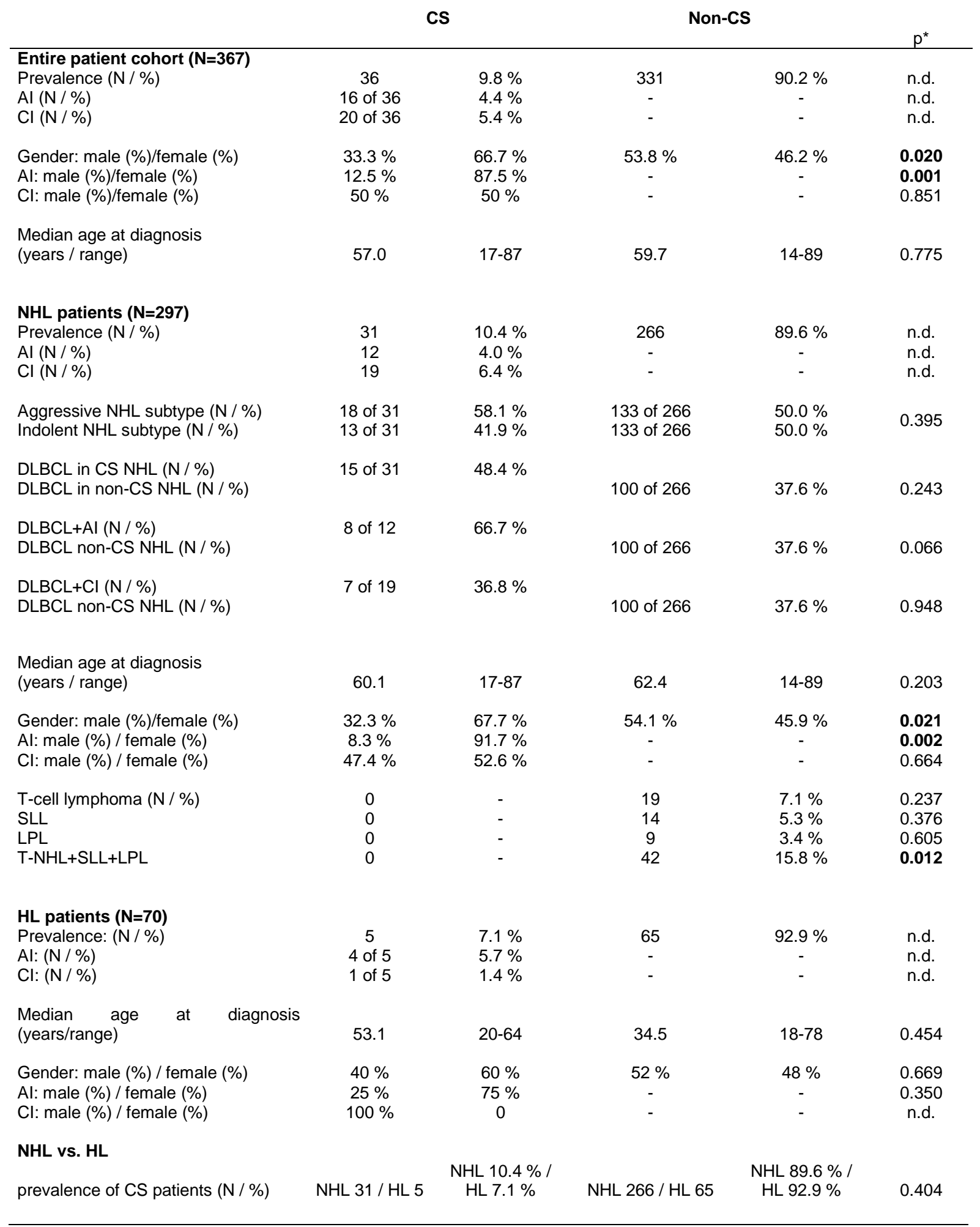


Figure 1: Overall survival (OS) of NHL patients with indolent or aggressive lymphoma subtype in relation to a history of chronic stimulation (CS) $(\mathrm{N}=297)$. The effect of $\mathrm{CS}$ on OS was not significantly different in indolent and aggressive lymphomas $(p=0.311)$.

Figure 2: Overall survival of $\mathrm{NHL}$ patients in relation to sex and chronic stimulation $(\mathrm{N}=297)$. (Male vs. female $p=0.072$; CS vs. non-CS $p=0.311$ in both men and women). 
Fig. 1

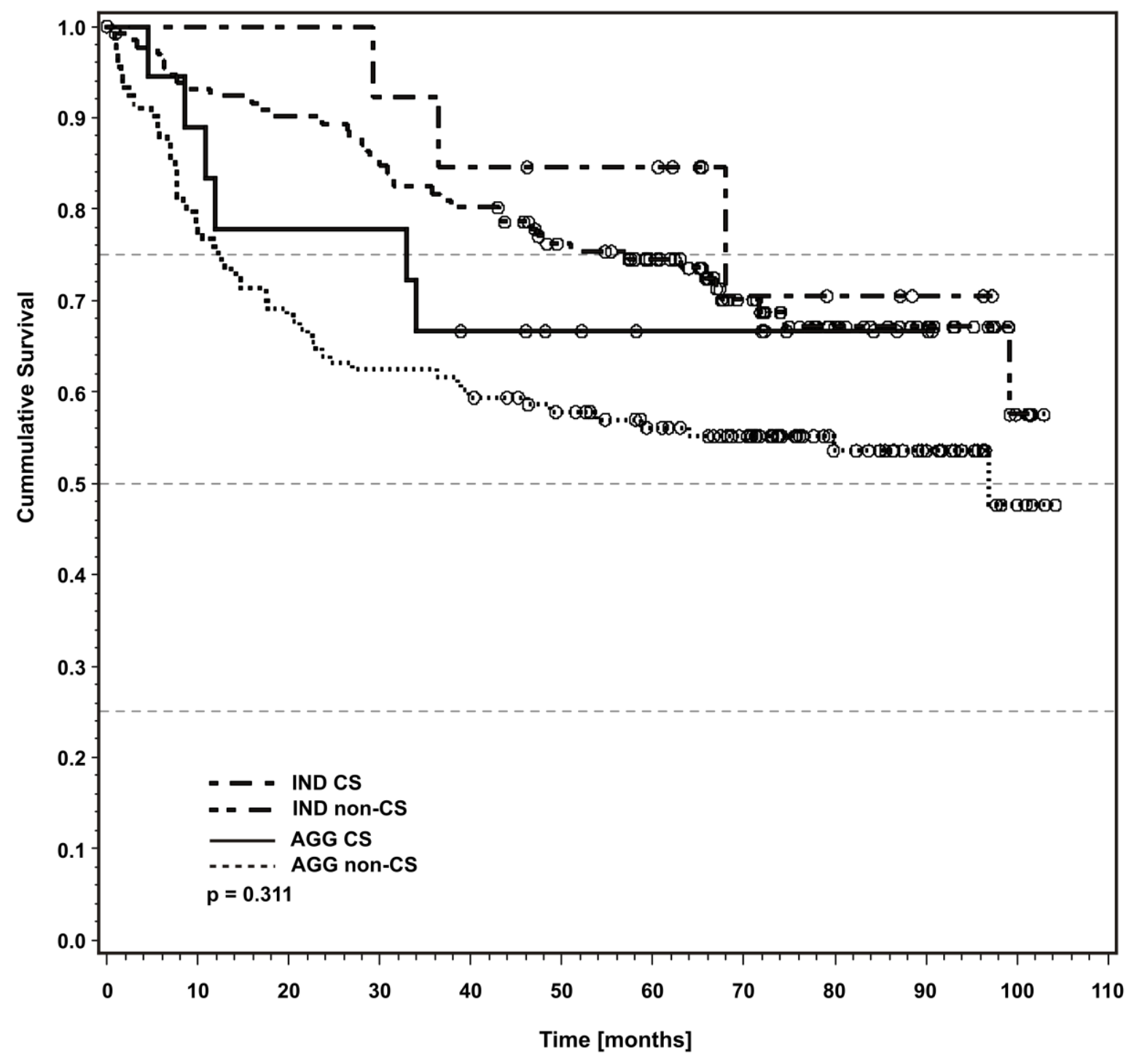


Fig. 2

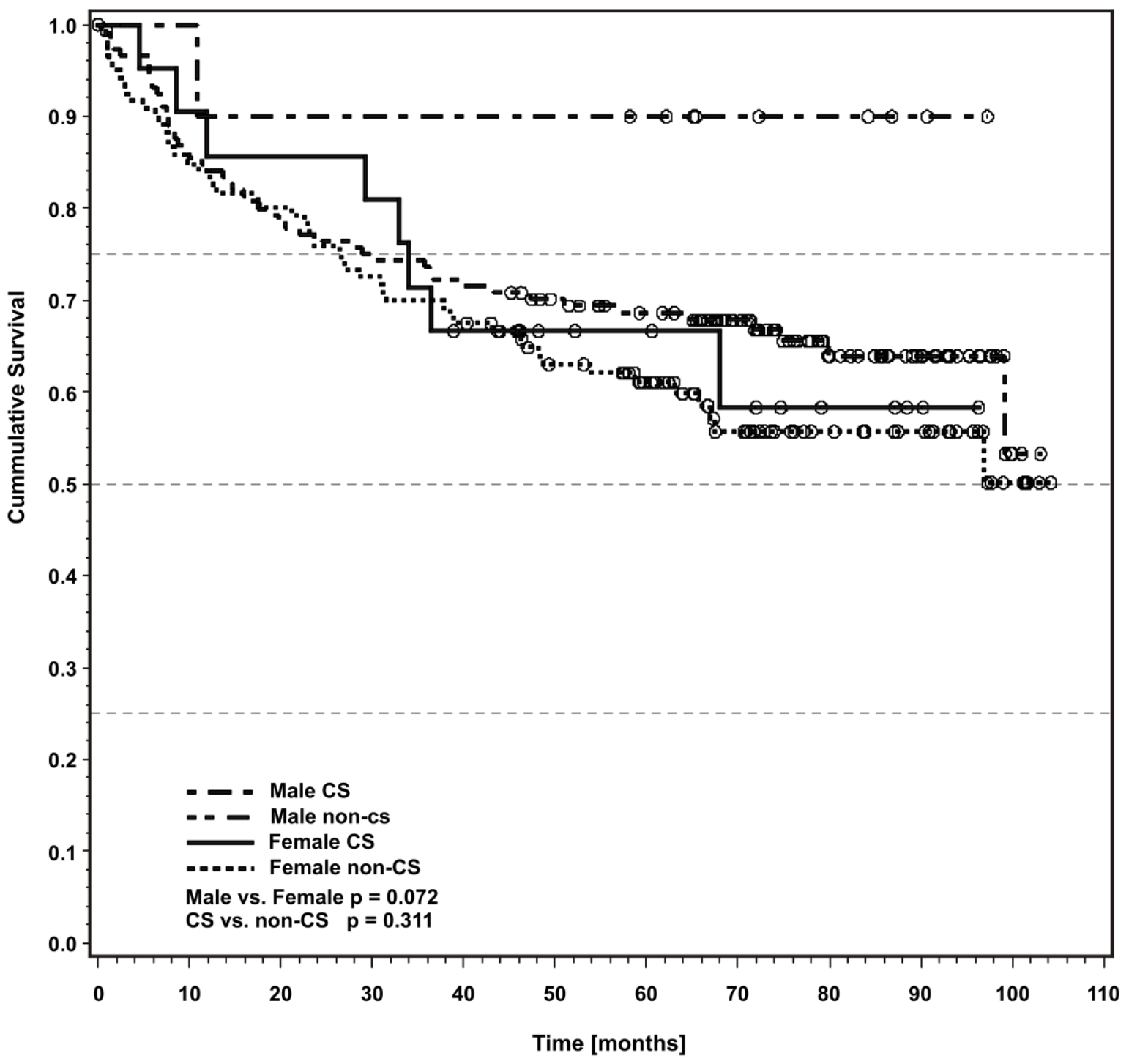

